\title{
Effect of cadmium telluride quantum dots on the dielectric and electro-optical properties of ferroelectric liquid crystals
}

\author{
A. Kumar and A. M. Biradar* \\ ${ }^{1}$ Liquid Crystal Group, National Physical Laboratory, Dr. K. S. Krishnan Road, New Delhi-110012, India \\ (Received 25 September 2010; revised manuscript received 17 January 2011; published 21 April 2011)
}

\begin{abstract}
We present here the dielectric and electro-optical studies of cadmium telluride quantum dots (CdTe QDs) doped ferroelectric liquid crystals (FLCs). It has been observed that the doping of CdTe QDs not only induced a pronounced memory effect but also affected the physical parameters of FLC material (LAHS19). The modifications in the physical parameters and memory effect of LAHS19 are found to depend on the concentration ratio of CdTe QDs. The lower concentration of CdTe QDs (1-3 wt \%) enhanced the values of spontaneous polarization and rotational viscosity of LAHS19 material but did not favor the memory effect, whereas a higher concentration of CdTe QDs ( $>5 \mathrm{wt} \%)$ degraded the alignment of LAHS19 material. The doping of $\sim 5 \mathrm{wt} \%$ of CdTe QDs is found to be the most suitable for achieving good memory effect without significantly affecting the material parameters.
\end{abstract}

DOI: 10.1103/PhysRevE.83.041708

PACS number(s): 61.30.-v, 42.79.Kr, 73.63.Kv

\section{INTRODUCTION}

The tunability of the electrical, optical, and other properties of nanomaterials with their size proved them to be very promising candidates for observing various important phenomena [1-3]. Among nanomaterials, the semiconductor nanoparticles (NPs) have attracted a great deal of attention due to their size dependent intense optical properties $[4,5]$. The quantum confinement phenomenon has been utilized to tune the optical properties of quantum dots (QDs). The QDs are very promising candidates for their possible applications in quantum computing, biology, photovoltaic devices, and light emitting diodes, etc. [6-9]. The charge storage capability of QDs has led to the emergence of a new concept: "QD memory." Different kinds of QDs have been employed as the charge trapping layer in various metal-insulator-semiconductor (MIS) structures. A large shift in the capacitance-voltage $(C-V)$ hysteresis of the metal-oxide-semiconductor (MOS) structures containing germanium QDs has been observed by Nassiopoulou et al. [10]. They attributed this shift in $C$ - $V$ hysteresis as the consequence of the charge trapping in deep traps of charging layer. The stored charges are difficult to erase and hence a limited memory window can be realized. Lee et al. observed memory effect in a MOS structure containing the zirconium $(\mathrm{Zr})$ nanocrystals embedded in $\mathrm{ZrO}_{2}$ dielectric layer [11]. They demonstrated that the memory behavior occurs on the basis of trapping of electrons in $\mathrm{Zr}-\mathrm{O}$ dangling bonds at the $\mathrm{ZrO}_{2}$ capping layer. It is also found that the charge carriers stored on QDs could persist over time scales exceeding seconds or even hours [12]. Recently, Nesheva et al. have demonstrated that the application of $10 \mathrm{~V}$ bias with duration of $1 \mathrm{sec}$ can create a positive net charge captured in some traps of amorphous Si QDs having a density of $6.8 \times 10^{11} \mathrm{~cm}^{-2}$ and $50 \%$ of this charge has been retained up to $24 \mathrm{~h}$ [13].

The promising properties of nanomaterials have drawn the continuous attention of researchers to utilize them effectively in various interdisciplinary research fields such as liquid

\footnotetext{
*Author to whom correspondence should be addressed. abiradar@mail.nplindia.ernet.in.
}

crystal (LC) to observe interesting phenomena. The gold NPs have been employed to improve electro-optical properties of LCs in the form of nonvolatile memory effect [14], enhanced photoluminescence of a newly synthesized deformed helix ferroelectric liquid crystal (DHFLC), namely, LAHS19 [15], and NPs induce LC alignment [16]. The semiconductor NPs such as $\mathrm{TiO}_{2}, \mathrm{ZnO}$ have been extensively utilized to achieve low power operation of LCs [17,18]. Kinkead and Hegmann [19] have observed that the size, capping agent, and concentration of different QDs play an important role in modifying the electro-optical properties such as lowering of threshold voltage and elastic constant of nematic LC mixtures. Shurpo et al. have observed the fast reorientation of LC molecules from planar to homeotropic position by introducing the CdSe/ZnS QDs into LC mixture [20]. However, the studies based on LC/QDs composites are based on nematic LCs and have been rarely reported in ferroelectric liquid-crystal (FLC) materials [21,22]. Recently, we observed a pronounced memory effect in FLC mixtures by doping few wt $\%$ of CdTe QDs [23]. This study has provided us further scope to observe the effect of CdTe QDs on the physical parameters of the FLC material to utilize effectively CdTe QDs for better memory devices.

In the present studies, the effect of CdTe QDs on dielectric and electro-optical properties of LAHS19 material has been observed by varying the doping concentrations of CdTe QDs. The addition of 1-3 wt \% of CdTe QDs has increased the values of spontaneous polarization $\left(P_{S}\right)$ and rotational viscosity $(\eta)$ of LAHS19 material but did not favor the memory effect. On the other hand, higher concentration ( $>5 \mathrm{wt} \%$ ) of CdTe QDs degraded the alignment of LAHS19 material. The doping of CdTe QDs has also affected the $\mathrm{SmC} C^{*}-\mathrm{Sm} A^{*}$ phase transition temperature of the FLC material. We found that the doping of $\sim 5 \mathrm{wt} \%$ CdTe QDs has induced a good memory effect in LAHS19 material without affecting much the physical constants of the material.

\section{EXPERIMENT}

The CdTe QDs have been synthesized in the form of poly(3hexylthiophenes) (P3HT)-CdTe nanocomposites in which the 


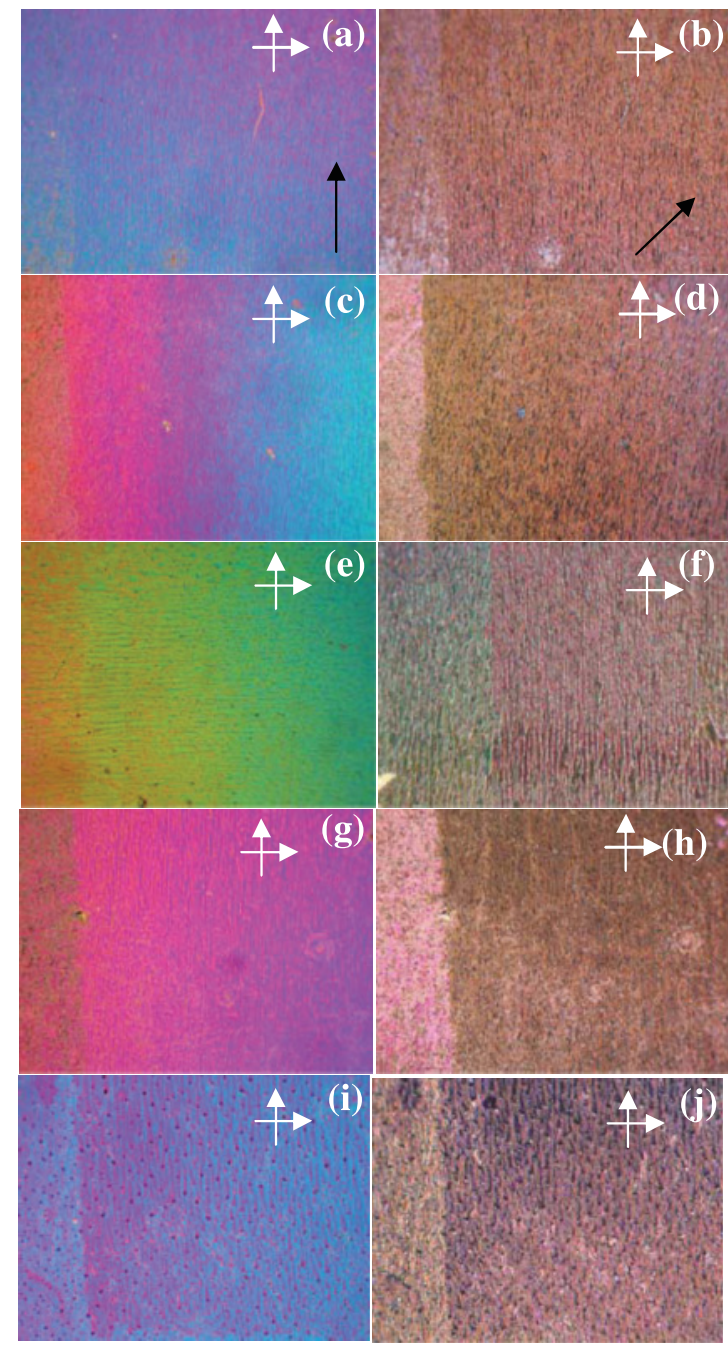

FIG. 1. (Color online) Polarizing optical micrographs of bright states (a), (c), (e), (g), (i) and dark states (b), (d), (f), (h), (j) of LAHS19 material doped with 0, 1, 2, 5, and $7 \mathrm{wt} \%$ CdTe QDs at room temperature (RT). The bright and dark states have been achieved by rotating the sample cell under a polarizing microscope. Crossed arrows show the crossed polarizers while single arrow shows the rotation (by $45^{\circ}$ ) of the sample cell (same for all samples) to obtain dark state. The thickness of sample cells was kept at $\sim 5 \mu \mathrm{m}$.

CdTe QDs were grown in situ in the P3HT matrix. The CdTe QDs were sandwiched between the P3HT polymer chains. The sulfur atom of P3HT interacts with the CdTe QDs by dipole-dipole interaction and CdTe QDs were deposited uniformly and compactly between the P3HT chains. The high resolution transmission electron micrograph images and electron diffraction pattern of the synthesized P3HT-CdTe nanocomposites revealed that the typical size of CdTe QDs varies between 2 and $7 \mathrm{~nm}$ in diameter [23]. The FLC sample cells were prepared using indium tin oxide (ITO) coated glass plates. The desired (squared) pattern area was $0.45 \times 0.45 \mathrm{~cm}^{2}$. The thickness of the cell was maintained $\sim 5 \mu \mathrm{m}$ by using Mylar spacers. The material LAHS19 doped with different concentrations (i.e., 1, 2, 5, and $7 \mathrm{wt} \%$ ) of CdTe QDs was filled into the cells by capillary action above the isotropic temperature. The material, LAHS19, possesses large values of
$P_{S}, \eta$, and ultrashort pitch value and comes under the category of deformed helix ferroelectric liquid crystals (DHFLCs). The molecular structure and physical parameters of this material have been reported earlier by us [15]. For homogeneous alignment of FLC cells, spin coating of polyimide (nylon 6/6) followed by smooth rubbing of the substrate were carried out using a spin coater and buffing machine, respectively. The phase sequence of FLC material used is as follows:

$$
\text { cryst. } \stackrel{7^{\circ} \mathrm{C}}{\longrightarrow} \mathrm{SmC}^{*} \stackrel{59.5^{\circ} \mathrm{C}}{\longrightarrow} \mathrm{Sm} A^{*} \stackrel{60^{\circ} \mathrm{C}}{\longrightarrow} \text { iso. }
$$

(LAHS19)

The dielectric relaxation spectroscopy of FLC/CdTe QDs mixtures is performed using an impedance analyzer (Wayne Kerr, 6540A, UK) in the frequency range $20 \mathrm{~Hz}-1 \mathrm{MHz}$ with measuring voltage of $0.5 V_{P P}$. The optical micrographs were taken using polarizing optical microscope (Carl Zeiss, Germany). The physical parameters such as $P_{S}, \eta$, and response time $\left(\tau_{R}\right)$ have been determined by an automatic LC tester (ALCT-P Instec, USA). The triangular pulses generated from a function generator were applied to the sample and were studied by using a storage oscilloscope (HM 1507-3, HAMEG, Germany) interfaced with the computer via SP-107 software. For optical response of the sample cells, a square

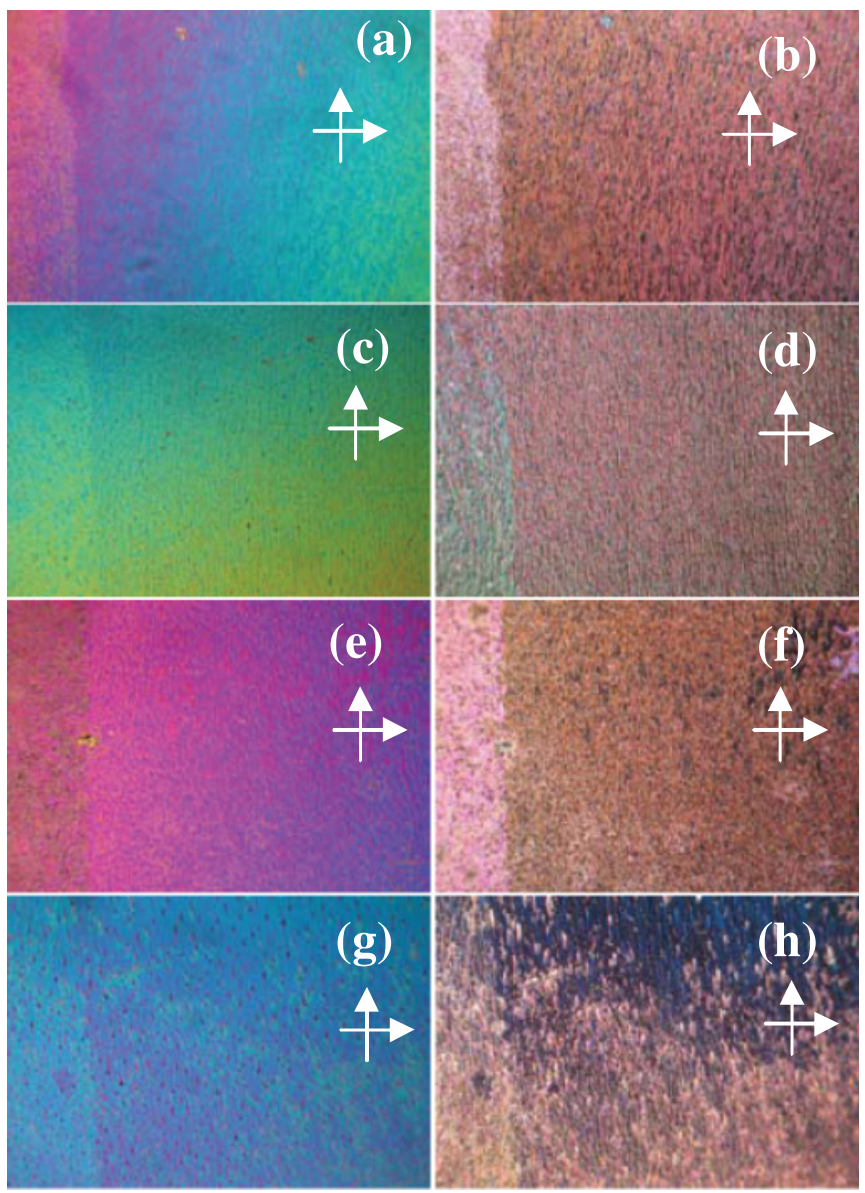

FIG. 2. (Color online) Polarizing optical micrographs of bright states (a), (c), (e), (g) and dark states (b), (d), (f), (h), of LAHS19 material doped with 1, 2, 5, and $7 \mathrm{wt} \%$ CdTe QDs taken after 80 days. 

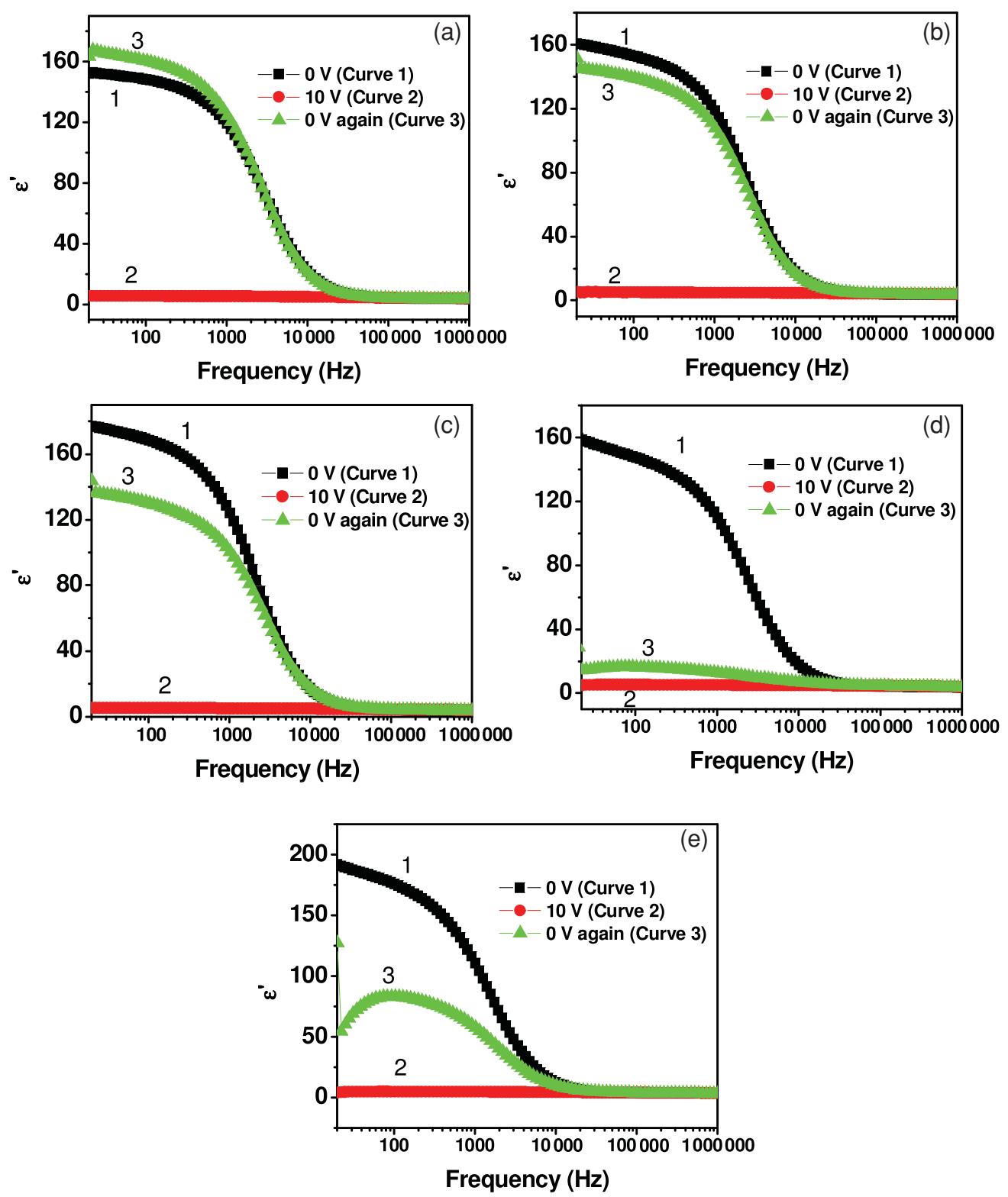

FIG. 3. (Color online) Behavior of dielectric permittivity $\left(\varepsilon^{\prime}\right)$ of LAHS19 material at different dc biases [0 V (curve 1), $10 \mathrm{~V}$ (curve 2), and $0 \mathrm{~V}$ again (curve 3)] doped with (a) 0, (b) 1, (c) 2, (d) 5, and (e) 7 wt\% of CdTe QDs at RT.

time delayed voltage pulse $\left(20 V_{P P}\right)$ from a function generator was applied to the sample and the change in the optical transmission was recorded using a photodiode interfaced with computer.

\section{RESULTS AND DISCUSSIONS}

Figure 1 shows optical micrographs of bright and dark states of 0, 1, 2, 5, and $7 \mathrm{wt} \%$ CdTe QDs doped LAHS19 material. The bright and dark states of the above samples have been achieved by rotating the sample under the crossed polarizer. It can be seen from Figs. 1(a)-1(h) that the doping of CdTe QDs up to $\sim 5 \mathrm{wt} \%$ does not perturb the alignment of LAHS19 material remarkably. However, the presence of CdTe QDs can be seen in the form of light scattering centers in both the bright and dark states of $\sim 7 \mathrm{wt} \%$ CdTe QDs doped LAHS19 [Figs. 1(i) and 1(j)]. The origin of light scattering centers can be understood by considering the fact that the dispersion of spherical and colloidal particles (such as cadmium sulphide QDs) into the LCs can introduce random surfaces which disrupt the uniformity of LC alignment [21,22]. The FLC alignment has affected remarkably by increasing the doping concentrations of CdTe QDs beyond $5 \mathrm{wt} \%$ which resulted in the form of degraded optical texture. The presence of a few tiny droplets can be clearly seen in the optical micrograph of $\sim 7 \mathrm{wt} \% \mathrm{CdTe}$ QDs doped LAHS19 [Figs. 1(i) and 1(j)]. This degradation of optical texture indicates that $\sim 5 \mathrm{wt} \%$ CdTe QDs is the limiting value which can be added to the LAHS19 material without any degradation in the FLC alignment. We have also analyzed the evolution of CdTe QDs aggregates over time by taking the optical micrographs of LAHS19/CdTe QDs mixtures after a longer duration. The optical micrographs of LAHS19/CdTe QDs mixtures taken after 80 days are shown in Fig. 2. No significant changes in the optical micrographs for CdTe QDs 
concentration up to $\sim 5 \mathrm{wt} \%$ were observed [Figs. 2(a)-2(f)]. However, a remarkable change in the case of $\sim 7 \mathrm{wt} \% \mathrm{CdTe}$ QDs doped LAHS19 material is observed [Figs. 2(g) and 2(h)]. The FLC molecules are arranged in a helical manner in the $\mathrm{Sm} C^{*}$ phase and show a higher value of dielectric permittivity $\left(\varepsilon^{\prime}\right)$ due to the contribution of the Goldstone mode (GM). The GM can be suppressed by the application of sufficient bias across the cell due to the unwinding of helical structure and results in the lower value of $\varepsilon^{\prime}$. On removal of bias, the FLC molecules attain their helical structure again due to restoring forces, and $\varepsilon^{\prime}$ reaches its original value. If FLC molecules retain their unwound state even after removal of bias then it means that the material exhibits memory. Figure 3 shows the behavior of $\varepsilon^{\prime}$ with frequency at different dc biases $[0,10$, and $0 \mathrm{~V}$ again (just after removal of bias)] of LAHS19/CdTe QDs mixtures at room temperature. The pure form of LAHS19 material did not show the memory effect, which can be seen from Fig. 3(a). The value of $\varepsilon^{\prime}$ reaches its original value (corresponding to the $0-\mathrm{V}$ state) just after removal of bias. The addition of $\sim 1 \mathrm{wt} \%$ CdTe QDs in LAHS19 material shows the glimpse of memory effect. The occurrence of memory effect has increased with the increase of the doping concentration of CdTe QDs, which can be seen from Figs. 3(c) and 3(d). The addition of $\sim 5 \mathrm{wt} \%$ of CdTe QDs has induced a pronounced memory effect in LAHS19 material [Fig. 3(d)] where the switched (corresponding to $10 \mathrm{~V}$ bias) state is almost retained even after removal of bias. When the doping concentration of CdTe QDs was further increased (beyond 5 wt $\%$ ), the alignment of LAHS19 material is affected remarkably, which in turn degraded the memory effect [Fig. 3(e)]. The persistence of memory effect was found to be dependent on both the concentration of CdTe QDs and the FLC material used. The memory state in the case of $\sim 5 \mathrm{wt} \%$ CdTe QDs doped LAHS 19 material was retained for more than 10 min whereas it was retained for a few minutes $(\sim 2-5 \mathrm{~min})$ in the case of $\sim 3 \mathrm{wt} \%$
CdTe QDs concentration in thick cells $(\sim 5 \mu \mathrm{m})$. The occurrence of memory effect in CdTe QDs doped LAHS19 material was attributed to the charge transfer from FLC molecules to CdTe QDs [23]. We found that the charges transferred to CdTe QDs can be retained there for some time, which in turn holds the nearby FLC molecules in their switched state (memory state). We found that the quantity of charge stored on the CdTe QDs is found to depend on the density (concentration) of CdTe QDs present in the LAHS19 material. The improvement in the memory behavior by increasing the doping concentration of CdTe QDs can be interpreted as a consequence of increase in the number of charge storing centers (CdTe QDs) into LAHS19 material. More and more FLC molecules come under the influence of CdTe QDs on increasing the doping concentration of the latter. The degradation of memory effect with higher doping concentrations ( $>5 \mathrm{wt} \%$ ) of CdTe QDs can be due to two facts. First, the agglomeration tendency of CdTe QDs is increased at higher doping concentrations which created large clusters of CdTe QDs that degrade the FLC alignment and hence the memory effect. Second, the Coulomb repulsion between electrons in the neighboring QDs is also increased on increasing their doping concentration [24].

The essential conditions for the occurrence of memory effect in DHFLC material (FLC 6304) have been demonstrated on the basis of resonance between helix unwinding-winding and molecular reorientation processes [25]. The authors explained that whenever a single peak was observed in the electrical response of the DHFLC material, a complete memory effect was observed. In the electrical response, a triangular wave pulse of desired amplitude and frequency was applied across the sample cell and the electrical response of output current was recorded using an oscilloscope. The output current response across the cell is a combination of three (resistive, capacitive, and dipolar reorientation of FLC molecules) currents [25]. We have observed the electrical response of LAHS19 material
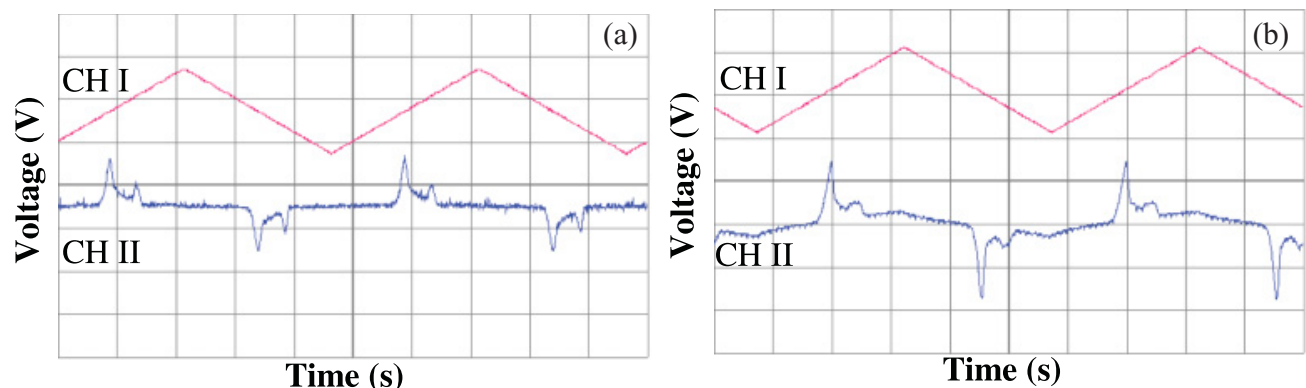

Time (s)

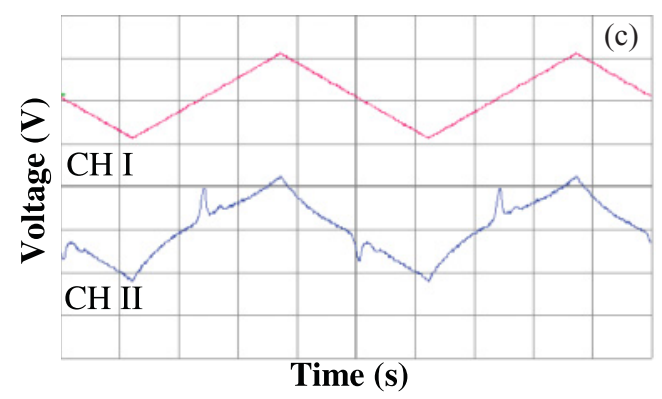

FIG. 4. (Color online) Electrical response of LAHS19 material doped with (a) 0, (b) 2, and (c) $5 \mathrm{wt} \%$ CdTe QDs at $200 \mathrm{mHz}$ frequency at RT. CH I shows the applied triangular voltage of amplitude $20 V_{P P}$ whereas CH II represents the output response across the sample cell. 

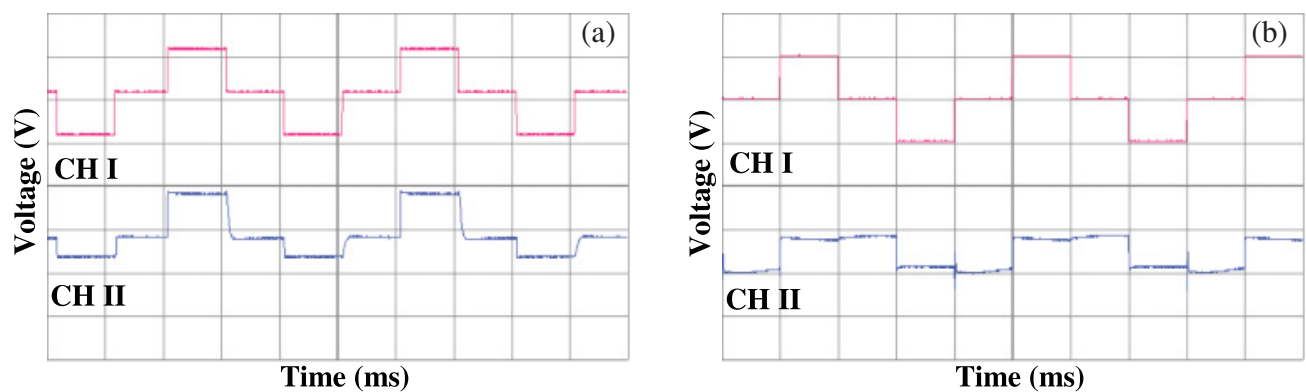

FIG. 5. (Color online) Optical response of LAHS19 material doped with (a) 2 and (b) $5 \mathrm{wt} \% \mathrm{CdTe}$ QDs at $500 \mathrm{mHz}$ frequency at RT. CH I shows the applied time delayed square voltage of amplitude $20 V_{P P}$ whereas $\mathrm{CH}$ II represents the output response of the sample cell.

doped with CdTe QDs at low frequency. Figure 4 shows the low frequency $(200 \mathrm{mHz})$ electrical response of pure and 1 , 2, and $5 \mathrm{wt} \%$ CdTe QDs doped LAHS19 material at room
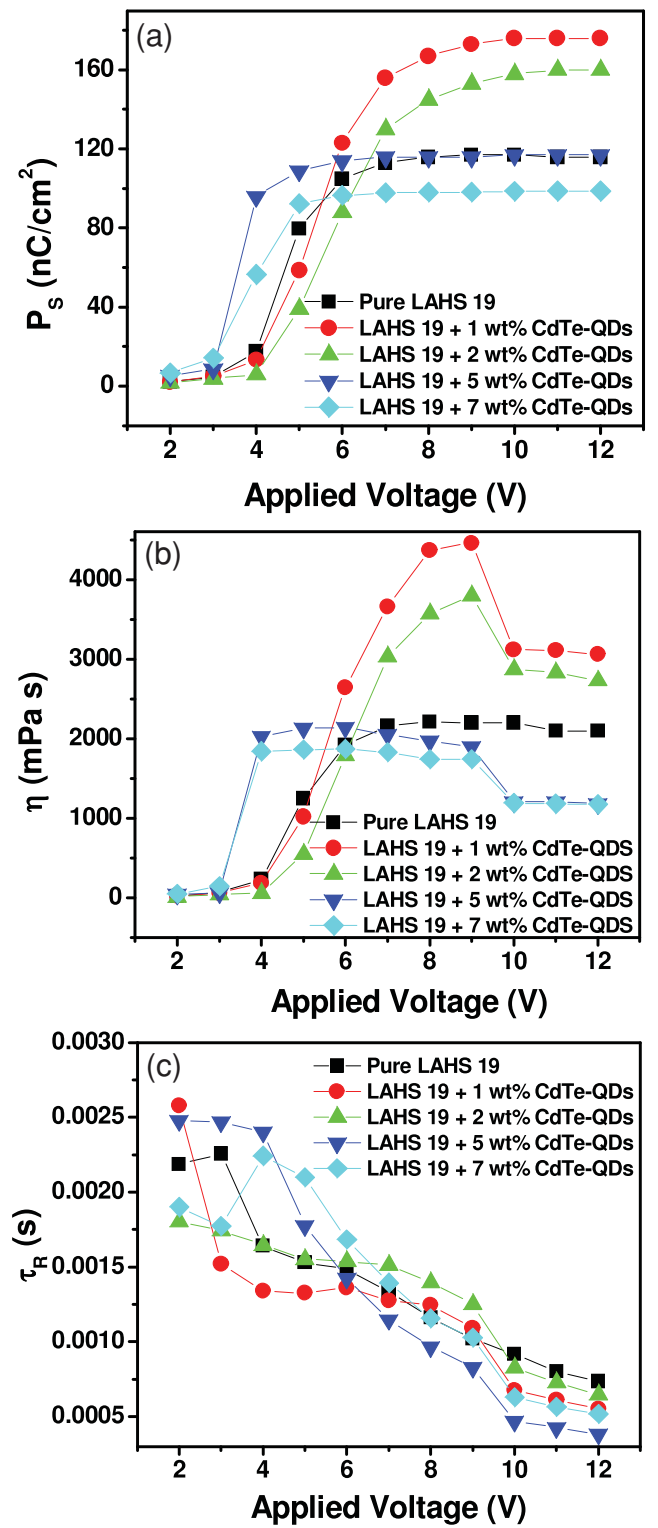

FIG. 6. (Color online) Behavior of physical parameters (a) $P_{S}$, (b) $\eta$, and (c) $\tau_{R}$ with applied voltage of LAHS19 material doped with different concentrations of CdTe QDs at RT. temperature. One can clearly see the occurrence of two peaks in the electrical response of pure LAHS19, which suggested the absence of resonance between helix unwinding-winding and molecular reorientation processes and hence no memory effect [Fig. 4(a)]. The amplitude of second peak in the electrical response of $\sim 1 \mathrm{wt} \%$ of CdTe QDs doped LAHS19 material was not only reduced, but the peak was shifted slightly toward the first peak [Fig. 4(b)]. The two peaks have almost merged to give a single peak on increasing the doping concentration of CdTe QDs to $~ 5 \mathrm{wt} \%$ [Fig. 4(c)]. The appearance of a single peak in electrical response of $\sim 5 \mathrm{wt} \%$ CdTe QDs doped LAHS19 supported the occurrence of memory effect. The occurrence of memory effect has also been confirmed by observing the optical response of the sample cells. Figure 5 shows the optical response of 2 and $5 \mathrm{wt} \%$ CdTe QDs doped LAHS19 material at $500 \mathrm{mHz}$ frequency. It is clear from Fig. 5(a) that the optical transmission in $2 \mathrm{wt} \%$ CdTe QDs doped LAHS19 almost follows the applied voltage pulse, which means no memory effect. But in the case of $\sim 5 \mathrm{wt} \%$ CdTe QDs doped LAHS19 almost complete optical memory was observed, as shown in Fig. 5(b). The optical transmission changes from maximum to minimum as the applied field reverses its polarity and there is almost no change when the applied field attains its $0-\mathrm{V}$ state [Fig. 5(b)]. We also observed the optical response of 0,1 , and $7 \mathrm{wt} \% \mathrm{CdTe}$ QDs doped LAHS19 material. The optical transmission in the case of pure and $1 \mathrm{wt} \%$ CdTe QDs doped LAHS19 material follows the same variation as input pulse in the whole frequency range, which suggests that there was no memory in these cases.

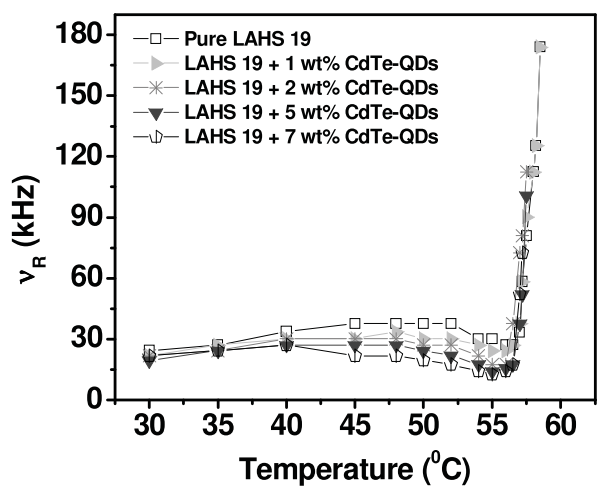

FIG. 7. Behavior of relaxation frequencies $\left(v_{R}\right)$ of LAHS19 material doped with different concentrations of CdTe QDs with temperature. 


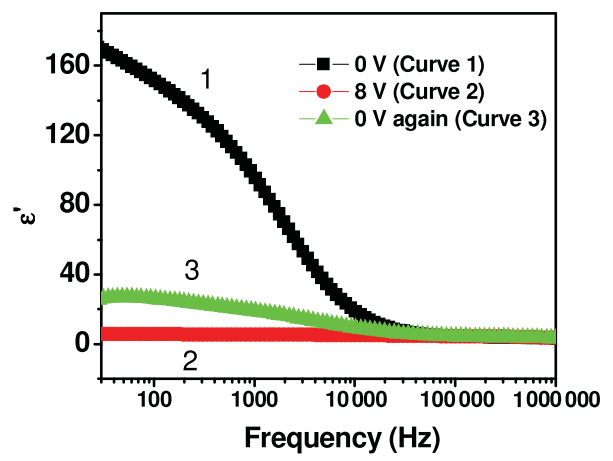

FIG. 8. (Color online) Behavior of dielectric permittivity $\left(\varepsilon^{\prime}\right)$ of LAHS19 material at different dc biases $[0 \mathrm{~V}$ (curve 1), $8 \mathrm{~V}$ (curve 2 ), and $0 \mathrm{~V}$ again (curve 3)] doped with $\sim 2 \mathrm{wt} \%$ of CdTe QDs in $\sim 2-\mu$ m-thick cell at RT.

The CdTe QDs have not only induced memory effect but also modified the physical parameters of LAHS19 material. Figure 6 shows the behavior of $P_{S}, \eta$, and $\tau_{R}$ of LAHS19/CdTe QDs mixtures with applied voltage at room temperature. The value of $P_{S}$ has been increased remarkably in the case of $\sim 1 \mathrm{wt} \%$ of CdTe QDs doped LAHS19 material [Fig. 6(a)]. When the doping concentration increased further from 1 to $7 \mathrm{wt} \%$, the value of $P_{S}$ was decreased and found least for $\sim 7 \mathrm{wt} \%$. However, the variation of $P_{S}$ with bias followed the same trend as that of pure LAHS19 material. It is worthwhile to notice here that the value of saturation voltage is larger $(\sim 8 \mathrm{~V})$ for the samples doped with lower concentrations (1 and $2 \mathrm{wt} \%)$ of CdTe QDs whereas it decreased $(\sim 5 \mathrm{~V})$ on increasing the doping concentrations and found minimum in the case of $\sim 5 \mathrm{wt} \%$. The modifications in the $P_{S}$ value of LAHS19 material when doping with different concentrations of CdTe QDs could be understood by taking into account the large dipole moment of semiconductor nanocrystals. Shim et al. have demonstrated the possible origin of large dipole moments and estimated 50-100 D as the range of dipole moment possessed by semiconductor NPs [26]. Recently, large permanent intrinsic dipole moment in InGaN/GaN QDs has also been observed by Ostapenko et al. [27]. The association of large dipole moment of CdTe QDs with that of DHFLC molecules has increased the effective $P_{S}$ of the mixtures. However, the $P_{S}$ has been decreased on increasing the doping concentration of CdTe QDs. There could be two reasons: first, the agglomeration of CdTe QDs was increased on increasing their doping concentration that may hinder the rotation of DHFLC molecules on application of electric field. Second, the numbers of DHFLC molecular dipoles per unit volume of the sample decreased on increasing the concentration of $\mathrm{CdTe}$ QDs. Figure 6(b) shows the behavior of $\eta$ of LAHS19/CdTe QDs mixtures with bias. We found that $\eta$ of LAHS19/CdTe QDs mixtures behaved in the same manner as that of $P_{S}$. The lower concentration of CdTe QDs has increased the $\eta$ greatly whereas it decreased on increasing the concentrations of CdTe QDs and became comparable to that of pure LAHS19 material. The electro-optic response time $\tau_{R}$ has also been calculated using the formula $\tau_{R}=\frac{\eta}{P_{\mathrm{S}} \times \mathrm{E}}$, where $E$ is the applied electric field.

The behavior of $\tau_{R}$ of LAHS19/CdTe QDs mixtures with applied voltage has been shown in the Fig. 6(c). The value of $\tau_{R}$ is decreased on increasing the concentrations of CdTe QDs and found minimum for $\sim 5 \mathrm{wt} \% \mathrm{CdTe}$ QDs doped LAHS19 material [Fig. 6(c)]. The CdTe QDs have also affected the saturation voltage of the LAHS19 material. The saturation voltage was found higher $(\sim 8 \mathrm{~V})$ in the case of the samples with lower concentrations ( 1 and 2 wt $\%$ ) of CdTe QDs and it was reduced on increasing the doping concentrations and found minimum in the case of $\sim 5 \mathrm{wt} \%$. The overall modifications in the physical parameters suggest that $\sim 5 \mathrm{wt} \%$ of CdTe QDs is suitable to induce pronounced

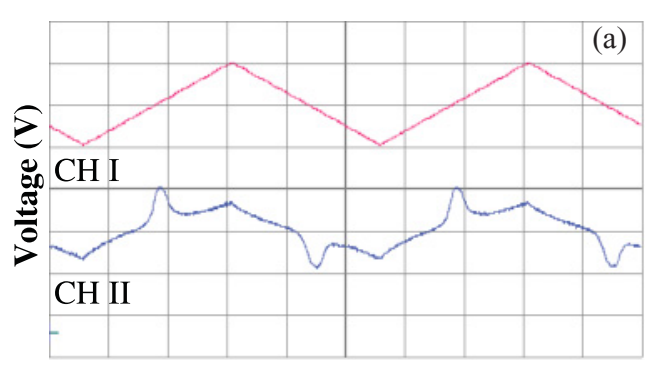

Time (s)

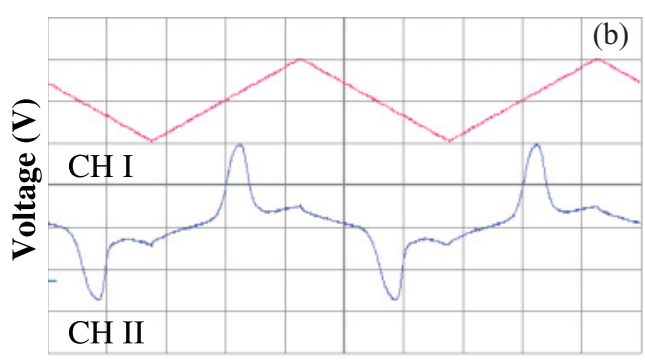

Time (ms)

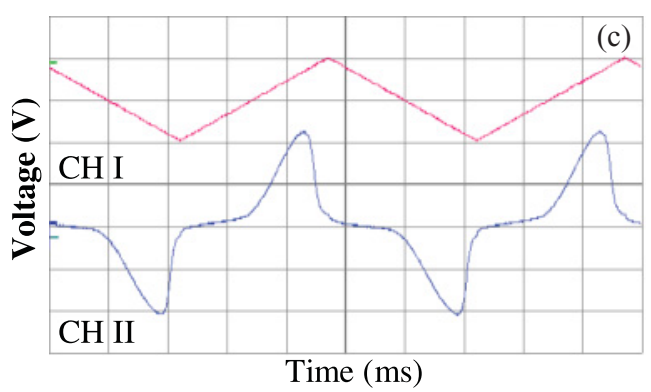

FIG. 9. (Color online) Electrical response of LAHS19 material doped with $\sim 2$ wt $\%$ CdTe QDs at (a) $200 \mathrm{mHz}$, (b) $500 \mathrm{mHz}$, and (c) $10 \mathrm{~Hz}$ frequencies in $\sim 2-\mu$ m-thick cell at RT. CH I shows the applied triangular voltage of amplitude $20 V_{P P}$ whereas $\mathrm{CH}$ II represents the output response across the sample cell. 

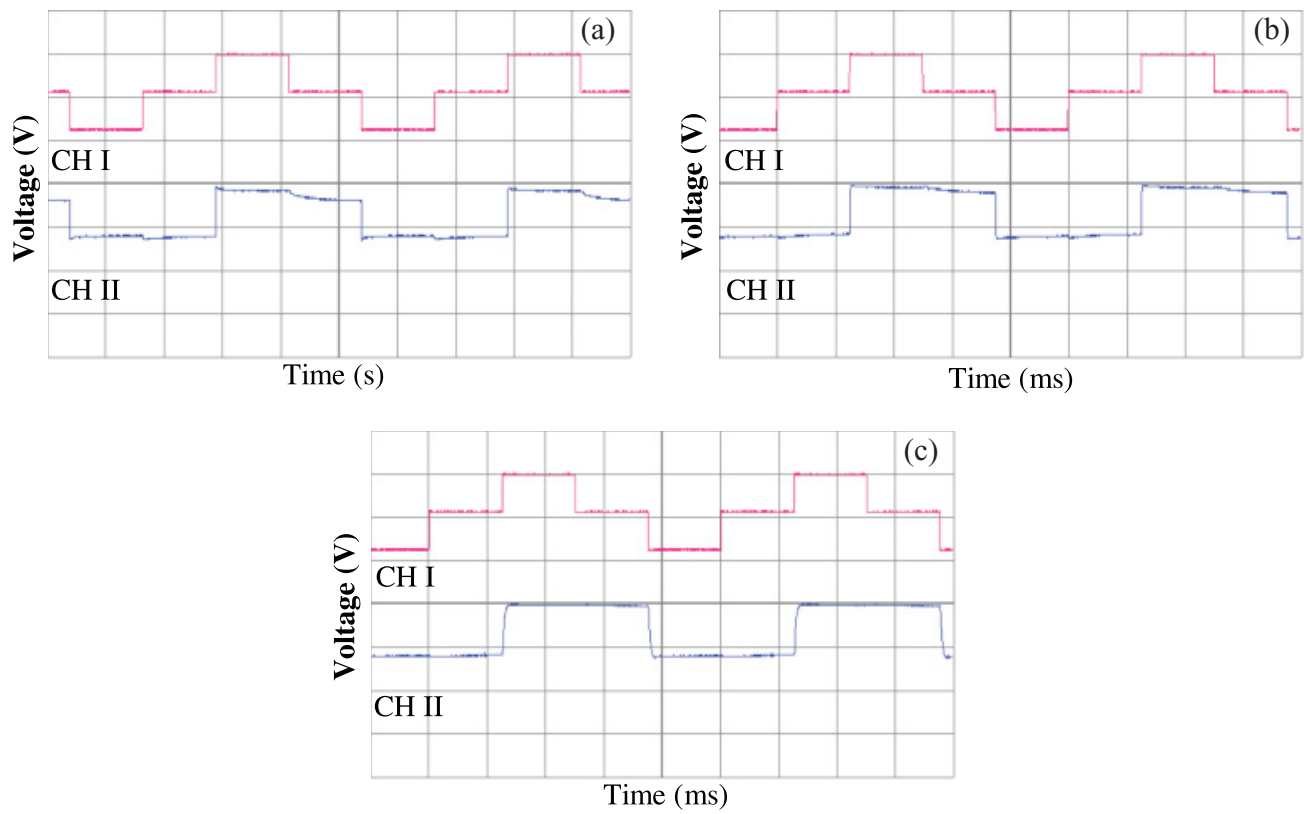

FIG. 10. (Color online) Optical response of LAHS19 material doped with 2 wt $\%$ CdTe QDs at (a) $200 \mathrm{mHz}$, (b) $500 \mathrm{mHz}$, and (c) $10 \mathrm{~Hz}$ frequencies in $\sim 2-\mu \mathrm{m}$-thick cell at RT. CH I shows the applied time delayed square voltage of amplitude $20 V_{P P}$ whereas CH II represents the output response of the sample cell.

memory effect without affecting the physical parameters of the LAHS19 material. The effect of CdTe QDs on the $\mathrm{Sm} C^{*}-\mathrm{Sm} A^{*}$ phase transition temperature $\left(T_{c}\right)$ have also been analyzed by observing the behavior of relaxation frequency (frequency at which the value of dielectric loss factor $(\tan \delta$ ) of GM is maximum) of CdTe QDs doped LAHS19 material with temperature. Figure 7 shows the behavior of $v_{R}$ with temperature for pure and CdTe QDs doped LAHS19 material. It is clear from Fig. 7 that the value of $v_{R}$ has been slightly decreased on increasing the concentration of CdTe QDs. The decrease in $v_{R}$ is found more remarkable when temperature approached $T_{c}$. The value of $T_{c}$ was reduced almost $\sim 1^{\circ} \mathrm{C}$ for $\sim 7 \mathrm{wt} \% \mathrm{CdTe}$ QDs doped LAHS19 material. The reduction in the $T_{C}$ could be understood as a consequence of the disordering of FLC molecules due to the presence of QDs.

We have also observed the effect of CdTe QDs on the memory behavior of LAHS19 material in a thin cell. For that, we made a $\sim 2-\mu \mathrm{m}$-thick cell using a photolithographic spacer and filled it with $\sim 2 \mathrm{wt} \%$ CdTe QDs doped LAHS19 material. It has been observed that the memory behavior of the thin cell is same as that observed for $\sim 5 \mathrm{wt} \%$ CdTe QDs doped LAHS19 material in $\sim 5-\mu \mathrm{m}$-thick cells (Fig. 8). On the other hand, the electro-optical performance in the case of the thin cell has been improved. Figure 9 shows the electrical response of $\sim 2 \mathrm{wt} \%$ CdTe QDs doped LAHS19 material in the thin cell at different frequencies. A clear single peak in the thin cell has been observed in the broad frequency range (200 $\mathrm{mHz}-50 \mathrm{~Hz}$ ). Figure 10 shows the optical response of $\sim 2 \mathrm{wt} \%$ CdTe QDs doped LAHS19 material in the thin cell at different frequencies. A complete optical memory has been observed for the thin cell in the whole frequency range (Fig. 10). We also observed the static memory state in the thin cell by applying a dc bias field across the sample and found that the memory state was retained for several (more than 24) hours (Fig. 11).
Figure 11(a) shows the optical micrograph of the scattering state (when no bias was applied) which on application of $5 \mathrm{~V}$ bias gets switched to give a bright field of view [Fig. 11(b)]. The switched state was retained for more than $24 \mathrm{~h}$ even after removal of bias, as can be seen from Figs. 11(c) and 11(d), which shows the micrographs of the cell after 1 and $24 \mathrm{~h}$ after removal of bias, respectively. The improvements in the electro-optical performance in the thin cell are due to better alignment of FLC molecules in thinner samples. We found that the use of the thin cell is more suitable to achieve improved electro-optical performance of CdTe QDs doped LAHS19 material.

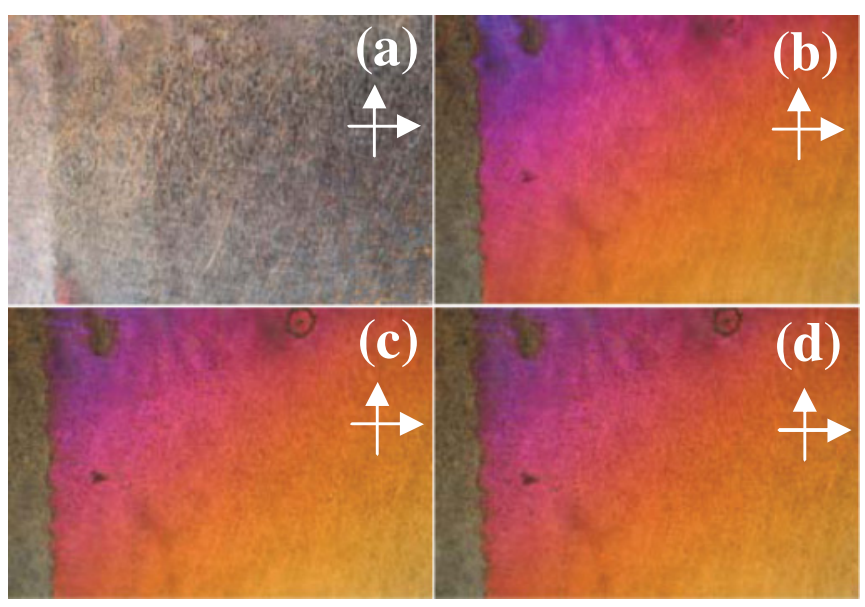

FIG. 11. (Color online) Polarizing optical micrographs (a) scattering state ( $0 \mathrm{~V}$ bias), (b) switched state ( $5 \mathrm{~V}$ bias), (c) $1 \mathrm{~h}$ after removal of bias, and (d) $24 \mathrm{~h}$ after removal of bias of $\sim 2 \mathrm{wt} \% \mathrm{CdTe}$ QDs doped LAHS19 material in thin cell $(2.2 \mu \mathrm{m})$ at RT. 


\section{CONCLUSIONS}

The effect of CdTe QDs on the memory behavior and physical parameters of a DHFLC material, namely LAHS19, has been presented. It has been observed that CdTe QDs have induced memory effect as well as modified the physical parameters of LAHS19 material. The memory behavior and physical parameters of the LAHS19 material are found to be highly dependent on the doping concentrations of CdTe QDs. A remarkable increase in the values of $P_{S}$ and $\eta$ has been observed for lower concentrations of CdTe QDs ( $<4 \mathrm{wt} \%$ ) doped into LAHS19 material. However, no remarkable enhancement in the memory behavior was observed for this concentration range. The values of $P_{S}$ and $\eta$ have been reduced and become comparable to that of pure LAHS19 material on increasing the doping concentration of CdTe QDs. The memory behavior has been degraded for higher concentration $(>5 \mathrm{wt} \%$ ) of CdTe QDs due to poor alignment of LAHS19 material. The doping of 4-5 wt\% of CdTe QDs is found to be the most suitable for achieving good memory effect without affecting the physical parameters of the LAHS19 material. The memory effect in the above system can be utilized in future zero power LC displays based on FLCs.

\section{ACKNOWLEDGMENTS}

The authors sincerely thank R. C. Budhani, Director, National Physical Laboratory, for continuous encouragement and interest in this work. The authors are thankful to W. Haase and his group of Technical University, Darmstadt, Germany, for supplying LAHS19 material as a gift. The authors are also thankful to Poonam Silotia, Department of Physics and Astrophysics, University of Delhi, and Jai Prakash, Instrument Design Development Centre, Indian Institute of Technology Delhi for fruitful discussions. The authors acknowledge S. K. Dhawan of Conducting Polymer Group for providing CdTe QDs. A.K. is thankful to University Grant Commission (UGC), New Delhi, for providing financial assistance.
[1] Vicki H. Grassian, J. Phys. Chem. C 112, 18303 (2008).

[2] H. M. Lu, Solid State Phenomena 155, 3 (2009).

[3] L. Liang, H. Ma, and Y. Wei, J. Nanomaterials 2011, 670857 (2011).

[4] R. Neuendorf, A. Brysch, G. Bour, and U. Kreibig, Proc. SPIE 4456, 39 (2001).

[5] M. Bangal, S. Ashtaputre, S. Marathe, A. Ethiraj, N. Hebalkar, S. W. Gosavi, J. Urban, and S. K. Kulkarni, Hyperfine Interact. 160, 81 (2005).

[6] M. G. Lagally, J. Chem. Ed. 75, 277 (1998).

[7] T. Jamieson, R. Bakhshi, D. Petrova, R. Pocock, M. Imani, and A. M. Seifalian, Biomaterials 28, 4717 (2007).

[8] E. Kikuchi, S. Kitada, A. Ohno, S. Aramaki, and S. Maenosono, Appl. Phys. Lett. 92, 173307 (2008).

[9] S.-H. Kang, H.-H. Huh, K.-C. Son, C.-S. Lee, K.-H. Kim, C. Huh, and E.-T. Kim, Phys. Status Solidi B 246, 889 (2009).

[10] A. G. Nassiopoulou, A. Olzierski, E. Tsoi, I. Berbezier, and A. Karmous, J. Nanosci. Nanotechnol. 7, 316 (2007).

[11] J. H. Lee, J. S. Choi, S. Hong, I. Hwang, Y.-I. Kim, S. J. Ahn, S.-O. Kang, and B. H. Park, Jpn. J. Appl. Phys. 46, L1246 (2007).

[12] T. Lundstrom, W. Schoenfeld, H. Lee, and P. M. Petroff, Science 286, 2312 (1999).

[13] D. Nesheva, N. Nedev, E. Manolov, I. Bineva, and H. Hofmeister, J. Phys. Chem. Solids 68, 725 (2007).

[14] J. Prakash, A. Choudhary, A. Kumar, D. S. Mehta, and A. M. Biradar, Appl. Phys. Lett. 93, 112904 (2008).
[15] A. Kumar, J. Prakash, D. S. Mehta, A. M. Biradar, and W. Haase, Appl. Phys. Lett. 95, 023117 (2009).

[16] H. Qi and T. Hegmann, Appl. Mater. Inter. 1, 1731 (2009).

[17] W.-K. Lee, J.-H. Choi, H.-J. Na, J.-H. Lim, J.-M. Han, J.-Y. Hwang, and D.-S. Seo, Opt. Lett. 34, 3653 (2009).

[18] T. Joshi, A. Kumar, J. Prakash, and A. M. Biradar, Appl. Phys. Lett. 96, 253109 (2010).

[19] B. Kinkead and T. Hegmann, J. Mater. Chem. 20, 448 (2010).

[20] N. A. Shurpo, M. S. Vakshtein, and N. V. Kamanina, Tech. Phys. Lett. 36, 319 (2010).

[21] R. Basu and G. S. Iannacchione, Phys. Rev. E 80, 010701 (2009).

[22] L. S. Hirst, J. Kirchhoff, R. Inman, and S. Ghosh, Proc. SPIE 7618, 76180F (2010).

[23] A. Kumar, J. Prakash, Mohd Taukeer Khan, S. K. Dhawan, and A. M. Biradar, Appl. Phys. Lett. 97, 163113 (2010).

[24] E. S. Kannan, G. H. Kim, and D. A. Ritchie, J. Phys. D 43, 225101 (2010).

[25] J. Prakash, D. S. Mehta, A. Choudhary, S. Kaur, V. Rathore, and A. M. Biradar, J. Appl. Phys. 103, 044103 (2008).

[26] M. Shim and P. Guyot-Sionnest, J. Chem. Phys. 111, 6955 (1999).

[27] I. A. Ostapenko, G. Hönig, C. Kindel, S. Rodt, A. Strittmatter, A. Hoffmann, and D. Bimberg, Appl. Phys. Lett. 97, 063103 (2010). 